Supporting Information: Self-Assembly of a Chiral Cubic Three-Connected Net from the High Symmetry Molecules $\mathrm{C}_{60}$ and $\mathrm{SnI}_{4}$

Daniel B. Straus* and Robert J. Cava*

Department of Chemistry, Princeton University, Princeton, NJ 08544 USA

*Authors to whom correspondence should be addressed. Email: dstraus@princeton.edu, rcava@princeton.edu 


\section{Additional Figures}

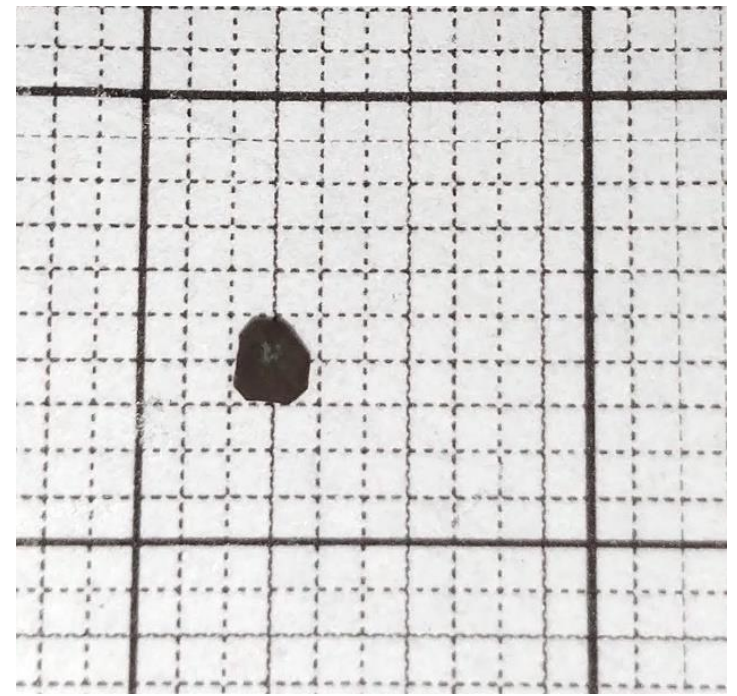

Figure S1: Photograph of representative $\mathrm{C}_{60}\left(\mathrm{SnI}_{4}\right)_{2}$ crystal on a mm grid (dashed lines).
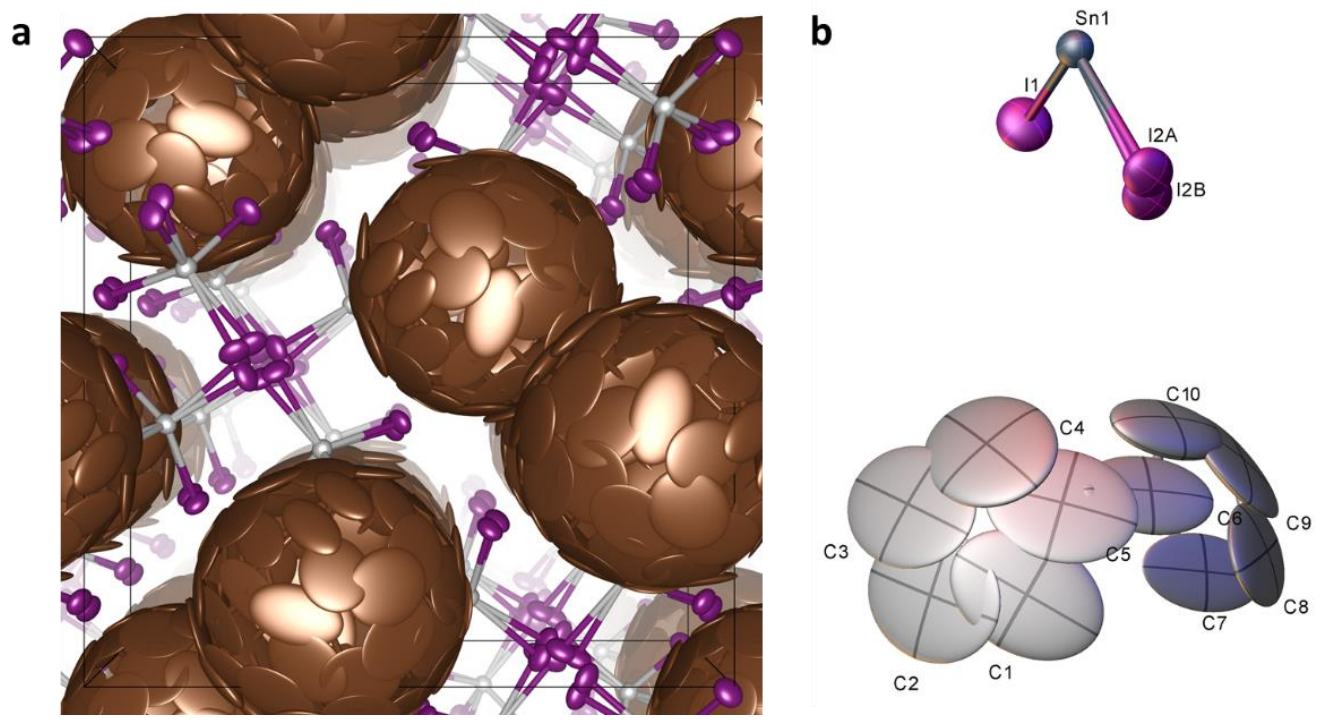

Figure S2: (a) $\mathrm{C}_{60}\left(\mathrm{SnI}_{4}\right)_{2}$ with both disordered I atoms, and (b) asymmetric unit. Atoms are represented as $50 \%$ probability thermal ellipsoids. (B) created using OLEX2. 


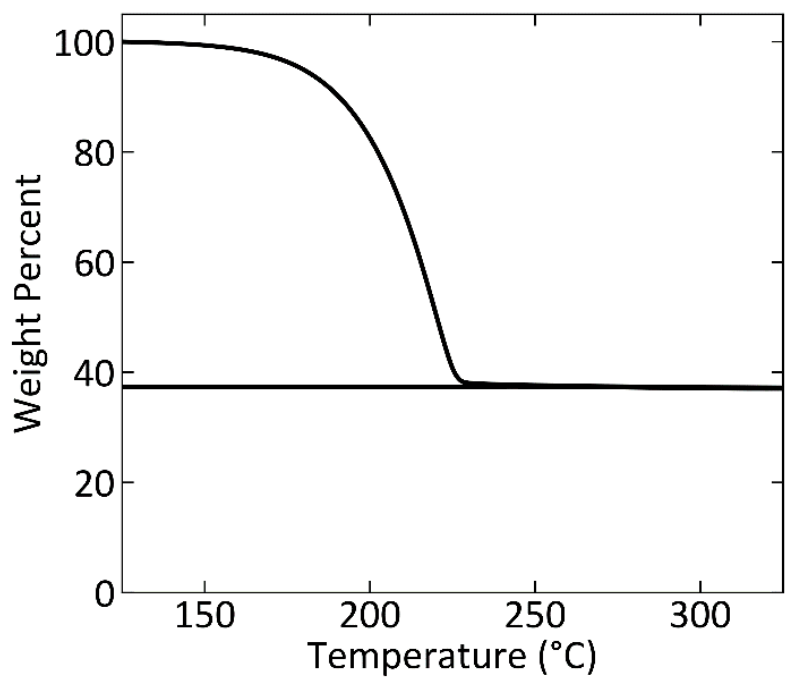

Figure S3: TGA of $\mathrm{C}_{60}\left(\mathrm{SnI}_{4}\right)_{2}$ single crystal heated at $0.5{ }^{\circ} \mathrm{C} / \mathrm{min}$.
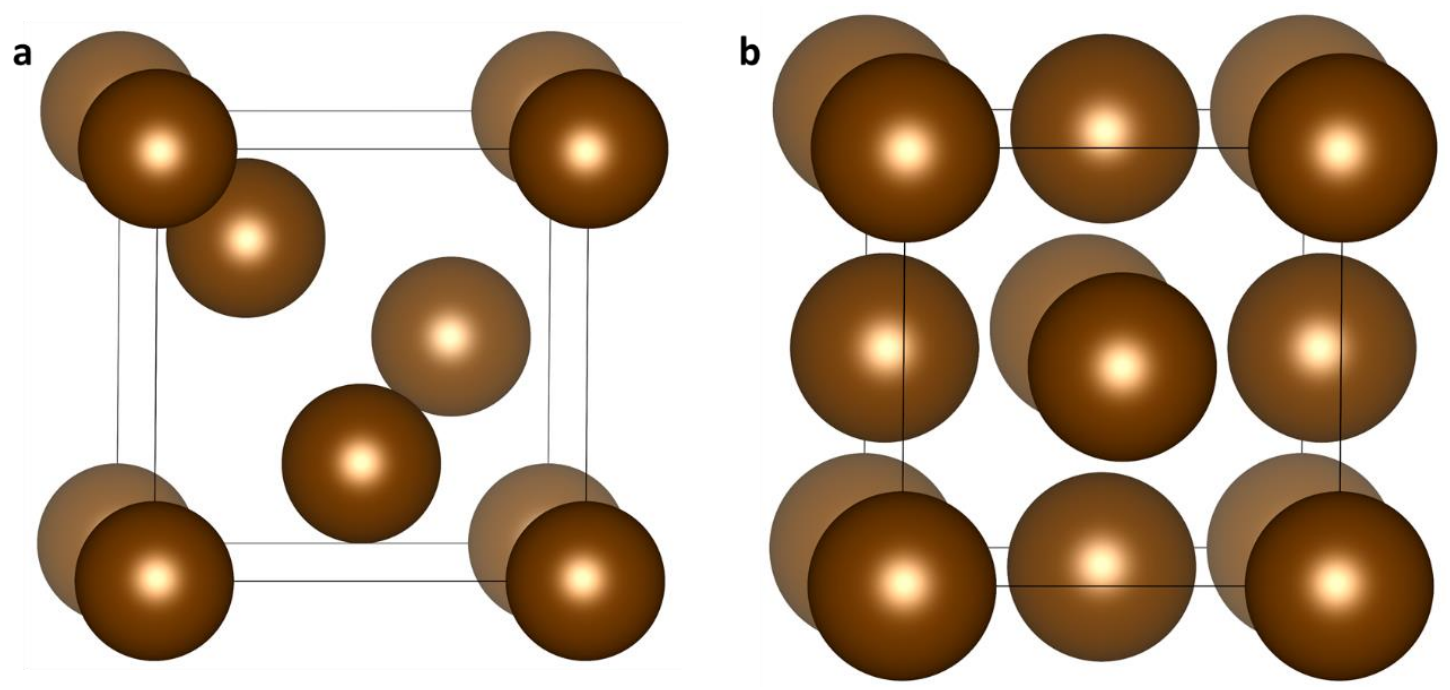

Figure S4: (a) The $\mathrm{C}_{60}$ atoms in $\mathrm{C}_{60}\left(\mathrm{SnI}_{4}\right)_{2}$ represented as spheres. The origin of the unit cell is shifted by $(1 / 8,1 / 8,1 / 8)$ to locate a $\mathrm{C}_{60}$ at each corner. (b) The $\mathrm{C}_{60}$ atoms in $\mathrm{FCC}_{60}$ represented as spheres. 

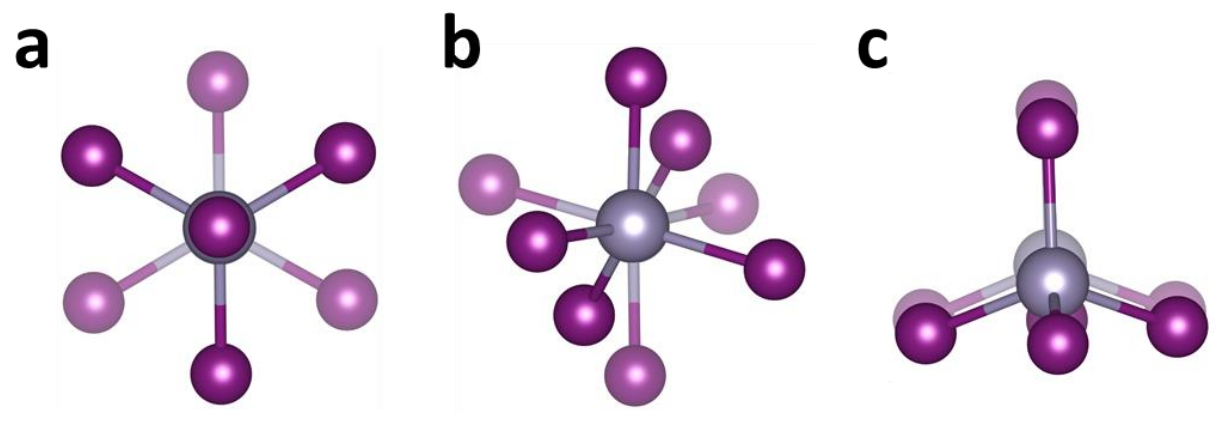

Figure S5: Views of (a) nearest, (b) next-nearest, and (c) next-next-nearest neighbor $\mathrm{SnI}_{4}$ tetrahedra down $\mathrm{Sn}-\mathrm{Sn}$ axis in crystalline $\mathrm{SnI}_{4}$.

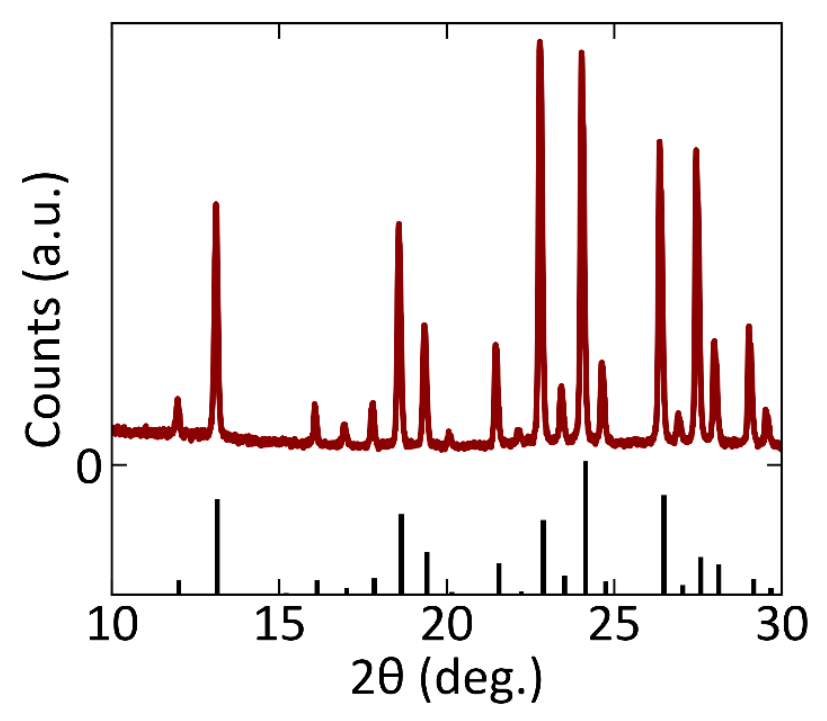

Figure S6: X-ray diffraction pattern of $\mathrm{C}_{60}\left(\mathrm{SnI}_{4}\right)_{2}$ synthesized by a solid-state method (dark red) with simulated powder diffraction pattern from single crystal structure (black). 


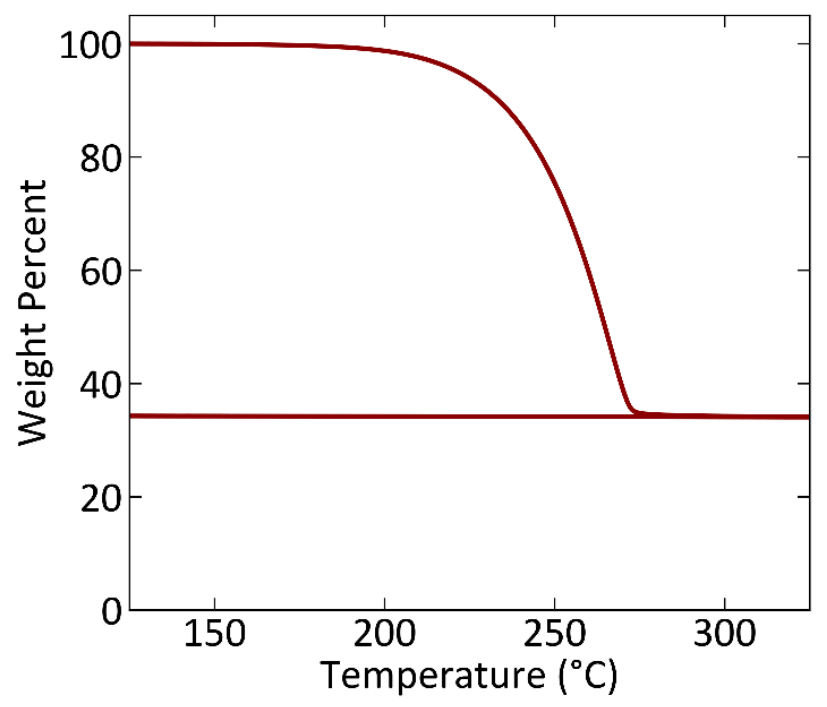

Figure S7: TGA of $\mathrm{C}_{60}\left(\mathrm{SnI}_{4}\right)_{2}$ powder from solid-state synthesis heated at $10{ }^{\circ} \mathrm{C} / \mathrm{min}$.

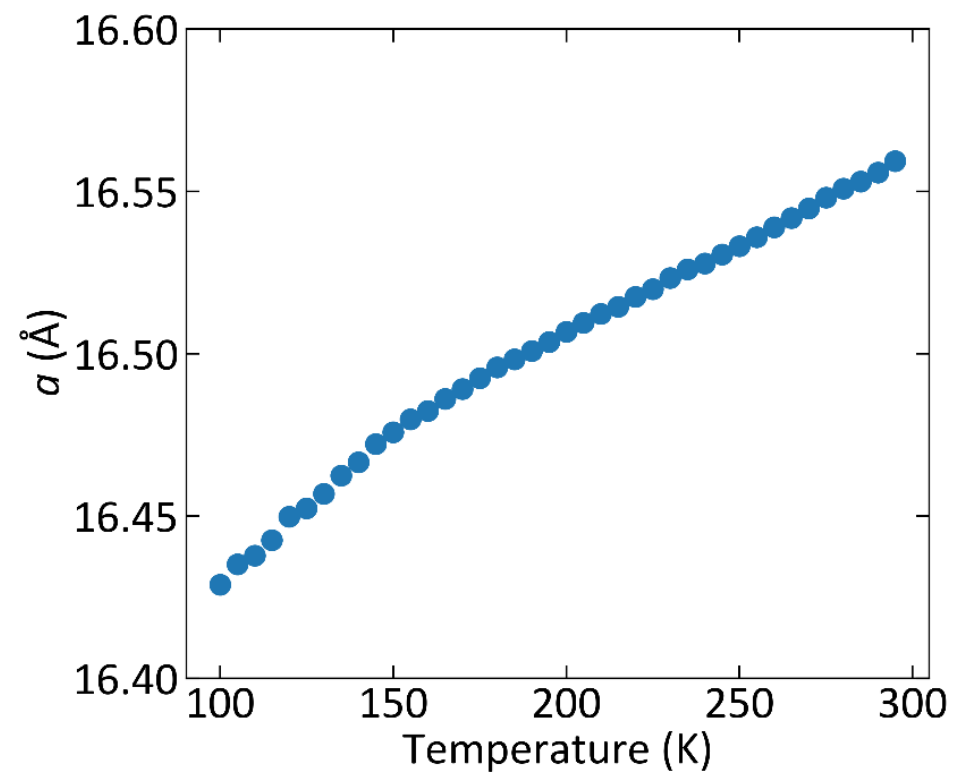

Figure S8: Temperature dependence of the lattice parameter of $\mathrm{C}_{60}\left(\mathrm{SnI}_{4}\right)_{2}$. 


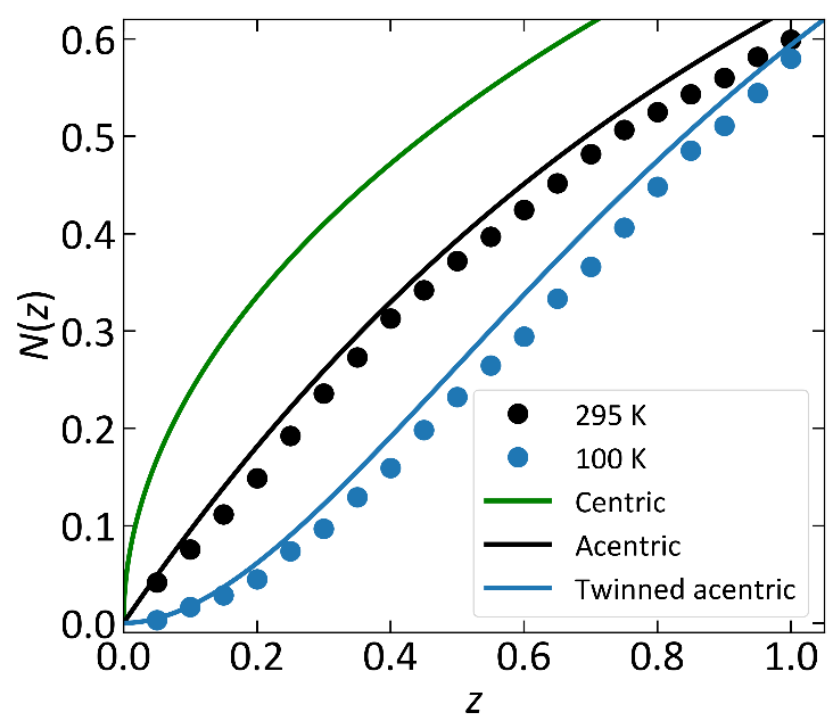

Figure S9: Cumulative intensity distribution for single crystal X-ray diffraction data at $295 \mathrm{~K}$ (black circles) and $100 \mathrm{~K}$ (blue circles) with ideal distributions for centric (green line), acentric (black line), and twinned acentric (blue line) crystals.

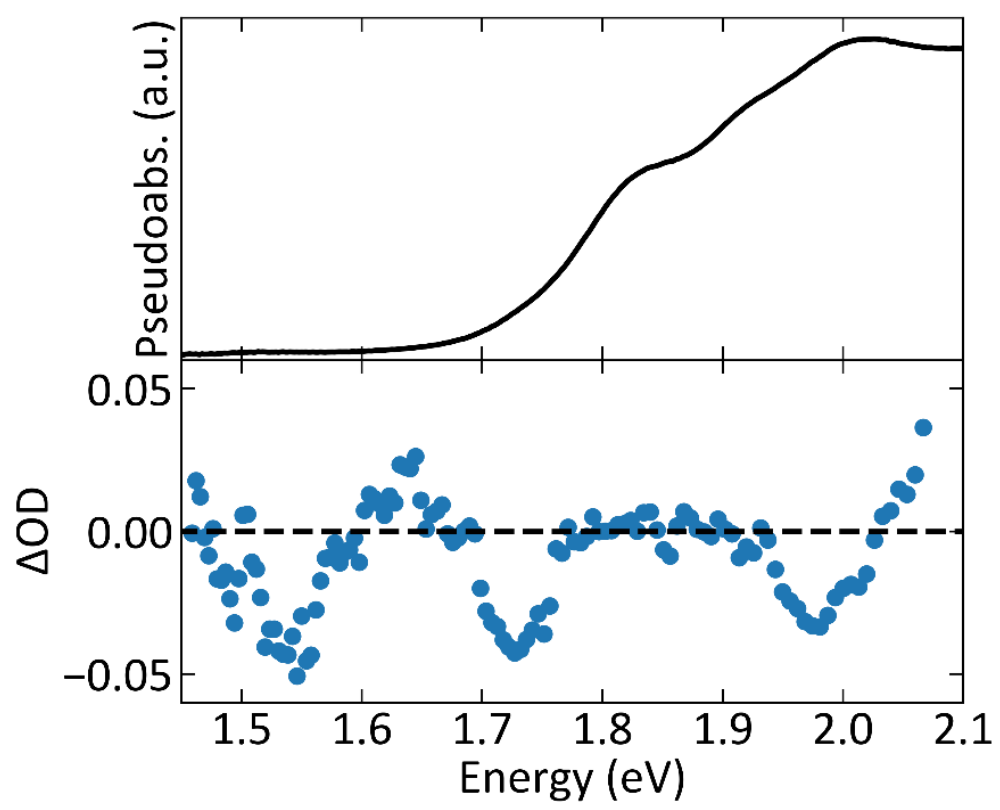

Figure S10: Circular dichroism spectrum (bottom) compared with pseudoabsorption spectrum (top). There are weak signatures of optical activity around the $1.5 \mathrm{eV}$ transition, the band edge (1.6-1.8 eV), and near $2.0 \mathrm{eV}$. 

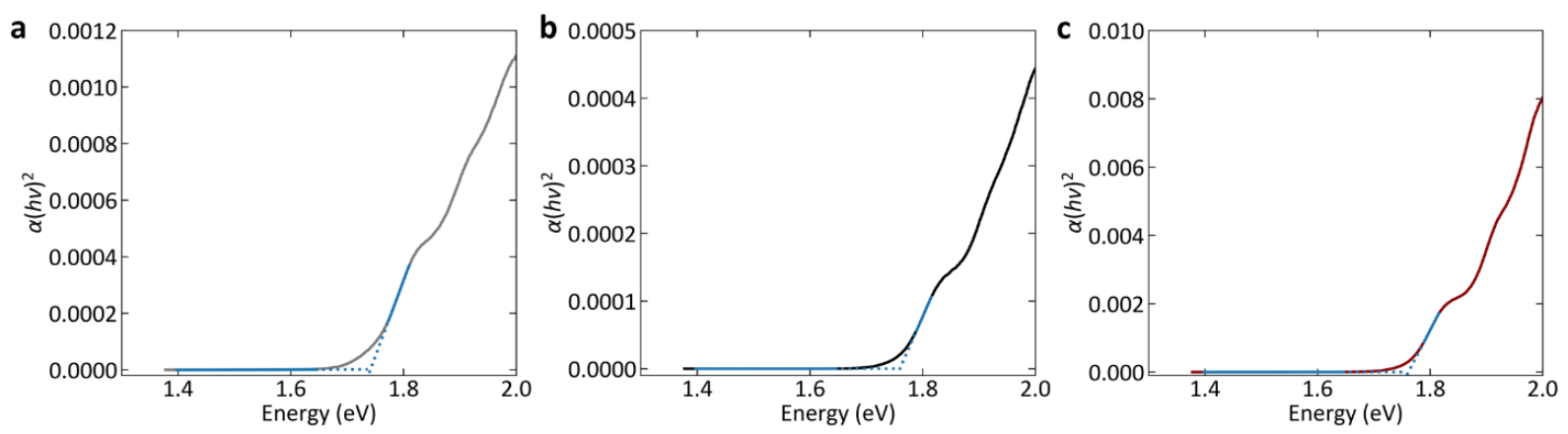

Figure S11: Tauc plots of (a) $\mathrm{C}_{60}$ and $\mathrm{C}_{60}\left(\mathrm{SnI}_{4}\right)_{2}$ synthesized (b) in solution and (c) in the solidstate. 